\title{
EDITORIAL
}

A pesquisa em paisagismo no Brasil, assim como a da arquitetura e do urbanismo, é fato relativamente novo quando comparado a áreas como história, geografia, medicina, tendo de fato se formalizado a partir da instalação dos primeiros programas de pós-graduação no país. No início dos anos 1990, apenas duas pessoas orientavam na área de paisagismo no Brasil, a Dra. Miranda Martinelli Magnoli e ev, atuando no programa de pós-graduação da FAUUSP, então estruturado em apenas uma área de concentração, denominada Estruturas Ambientais Urbanas. Na época, cada um de nós orientava concomitantemente mais de uma dezena de alunos entre mestrandos e doutorandos.

Iniciei nesses tempos minha primeira pesquisa solo, que mais tarde deu origem à tese de livre docência intitulada Paisagem, urbanização e litoral: do éden à cidade, que posteriormente me permitiu colaborar com o Projeto de Gestão Integrada da Orla Marítima (Projeto Orla), programa de regularização da orla brasileira do Ministério do Meio Ambiente. Foi também no início dos anos 1990 que empreendemos a pesquisa Quadro do Paisagismo no Brasil, que originaria o projeto de pesquisa homônimo - atualmente em sua quinta fase -, proporcionando a formação de inúmeros pesquisadores.

Nessa mesma época, fui orientador do professor Vicente Barcellos Quintella, da Universidade Nacional de Brasília (UnB), cuja tese Os Parques como Espaços Livres Públicos de Lazer: o caso de Brasília, proporcionou discussões sobre o parque no Brasil. Mais que meu orientando, Vicente se tornou um colaborador e amigo com quem tive oportunidade de desenvolver diversos trabalhos, contribuindo de modo decisivo para a constituição e consolidação da rede de pesquisa Quapá-SEL, com participação ativa em suas atividades, especialmente nos colóquios anuais.

Vicente foi, de fato, um dos pioneiros da segunda fase de pesquisadores em paisagismo no país, com uma pesquisa consistente sobre parques. Nos últimos anos, vinha se dedicando ao estudo das paisagens e dos sistemas de espaços livres das novas cidades situadas nas fronteiras agrícolas do Centro-Oeste e Sudeste brasileiros, como Lucas do Rio Verde e Luís Eduardo Magalhães. De modo bastante cuidadoso, estudou suas estruturas morfológicas e espaciais, produzindo uma série de textos pioneiros: As supernovas: duas futuras cidades brasileiras, publicado na edição 29; os textos Novas paisagens urbanas brasileiras: Luís Eduardo Magalhães, Novas paisagens urbanas brasileiras: Lucas do Rio Verde (MT) e Novas cidades de Mato Grosso, publicados nos livros Quadro dos sistemas de espaços livres nas cidades brasileiras e Sistema de espaços livres: conceitos, conflitos e paisagens, resultados das pesquisas da rede Quapá-SEL, editados pela FAUUSP.

Vicente faleceu em novembro de 2015, deixando saudade para seus amigos e colegas pesquisadores e a lembrança de um professor e pesquisador sério (com sua 
tranquilidade carioca), de um parceiro que várias vezes me hospedou em sua casa, em Brasília, primeiro no apartamento da Asa Sul, depois na casa do Lago Norte, sempre tranquilo e pronto a discutir as questões da paisagem brasileira e contar os casos de sua experiência de vida na África e pelo Brasil afora. Enfim, um grande amigo. Esta edição da revista Paisagem e Ambiente: ensaios é dedicada ao Vicente, que nos deixou um legado importante, o do pesquisador curioso, sempre em busca de novos fatos e ideias. Obrigado, Vicente, pelo privilégio de sua companhia.

Neste número apresentamos novas gerações de pesquisadores, alguns associados a pesquisadores já tradicionais da área, com artigos que são produtos e resultados de pesquisas consistentes que nos ajudam a entender um pouco mais a paisagem e o paisagismo brasileiro.

Na seção Paisagem Urbana, o texto Empreendimentos e ações públicas e privadas em Maceió/AL no início do milênio, de autoria de Verônica Robalinho Cavalcanti, Geraldo Majela Gaudêncio Faria, Viviane Regina Costa, Luiz Gustavo Oliveira da Silva e Luan Rubens Dias de Moura, é produto de pesquisas do grupo liderado por Geraldo, que desenvolve importante trabalho de pesquisa sobre a cidade de Maceió. $\bigcirc$ artigo exibe um painel consistente da paisagem em construção na cidade, que nesta década apresenta importante processo de transformação e expansão de sua área urbana, com a criação de novas fronteiras urbanas sobre as áreas de tabuleiro, com a consequente criação de conflitos ambientais.

Avaliação do caráter da paisagem: abordagens europeias, de Virginia Gomes de Luca e Alina Gonçalves Santiago, pode ser apreciado na seção Fundamentos. O artigo introduz o estudo da paisagem a partir de preceitos desenvolvidos pela Convenção Europeia da Paisagem (CEP) - que, aprovada em 2000, em Florença, permite um modo interessante de interpretação das paisagens em transformação. A dra. Alina Santiago, professora e pesquisadora da Universidade Federal de Santa Catarina (UFSC), lidera um importante grupo de pesquisa, tendo importante papel na constituição das bases teóricas do paisagismo nacional.

Três artigos compõem a seção Meio Ambiente. O primeiro, Espaços livres e morfologia urbana: discussões sobre influências na qualidade climática e sustentabilidade urbana a partir de estudos em cidades no Estado de Alagoas, Brasil, de Gianna Melo Barbirato, Simone Carnaúba Torres e Ricardo Victor Rodrigues Barbosa, reflete sobre morfologia urbana, espaços livres e sua relação com a adequação climática e a sustentabilidade urbana nas cidades de Maceió e Arapiraca (AL). O segundo, de Clibson Alves dos Santos e Larissa Gischewski Guimarães, Análise ambiental como subsídio ao planejamento urbano: o caso de Boa Esperança (MG), estuda as bacias hidrográficas urbanas do município. Fecha a seção Rios urbanos e paisagens multifuncionais: estudo de caso - rio Dona Eugênia, de lanic Bigate Lourenço, Aline Pires Veról, Marcelo Gomes Miguez e Ana Lucia Nogueira de Paiva Britto, mostrando como a introdução de critérios paisagísticos pode levar a melhor inserção urbana de corpos fluviais.

Presente na seção Pesquisa, $O$ emprego da fotografia como método de análise da transformação da paisagem: o caso de Anchieta, dos autores Giovani Bonadiman Gol- 
tara e Eneida Maria Souza Mendonça, importante pesquisadora da área de desenho e paisagem urbana da Universidade Federal do Espirito Santo (UFES), mostra o papel da fotografia como instrumento de leitura da transformação da paisagem urbana, utilizando como estudo de caso a fronteira sul da Região Metropolitana da Grande Vitória.

A seção Espaços Livres traz o texto Utilização de multimétodos de caracterização e análise da paisagem e dos espaços livres intraurbanos de Santa Maria (RS), de Luis GuiIherme Aita Pippi, Letícia de Castro Gabriel, Renata Michelon Cocco, Letícia de Fátima Durlo Coutinho, Henrique Schwingel e Marcos Guterres Giovelli. O grupo apresenta procedimentos de análise dos espaços livres urbanos da cidade de Santa Maria, resultado de trabalho coordenado pelo dr. Luis Guilherme A. Pippi. Outro artigo da mesma seção, Parques urbanos: fragilidade na aplicação de legislação específica no município de Chapecó (SC), de Angela Favarettto, Juliana Rammé e Sonia Afonso, que é professora e pesquisadora da UFSC, faz uma crítica ao papel dos Planos Diretores da cidade na constituição dos parques locais. Por fim, Maria Alice Medeiros Dias e Marcos Pereira Diligenti mostram a polêmica envolvendo a inserção de uma escultura emblemática na paisagem de Porto Alegre no texto $\bigcirc$ Laçador: espectro de significação e identidade.

Esta edição é a primeira processada online, o que nos permitiu agilizar o processo de avaliação e inscrição de artigos, fato que se rebaterá em um processo mais dinâmico de avaliação dos trabalhos e editoração da revista.

\section{Dr. Silvio Soares Macedo}

\section{Editor}

\section{Dezembro/2015}

